OPEN ACCESS

Edited by:

Con Stough,

Swinburne University of

Technology, Australia

Reviewed by:

Beata Mrugalska,

Poznań University of

Technology, Poland

Mario Lanza,

King Abdullah University of Science

and Technology, Saudi Arabia

*Correspondence:

Jingjing Zeng

jjzeng@zuel.edu.cn

Specialty section:

This article was submitted to

Organizational Psychology,

a section of the journal

Frontiers in Psychology

Received: 30 March 2021

Accepted: 16 August 2021

Published: 17 September 2021

Citation:

Wu F, Su J and Zeng J (2021) How Does the Chinese Government Select

and Funding High-Level Talents? An

Empirical Study Based on the

Resumes of Talents.

Front. Psychol. 12:687447.

doi: 10.3389/fpsyg.2021.687447

\section{How Does the Chinese Government Select and Funding High-Level Talents? An Empirical Study Based on the Resumes of Talents}

\author{
Fan $W u^{1}$, Jialin $S u^{1}$ and Jingjing Zeng ${ }^{2 *}$ \\ ${ }^{1}$ School of Public policy and Management, Guangxi University, Nanning, China, ${ }^{2}$ School of Public Administration, Zhongnan \\ University of Economics and Law, Wuhan, China
}

Based on the textual data of the resumes of 499 high-level talents, this study attempts to explore the factors affecting the selection and funding of high-level talents in western China. From the empirical analysis, we found that (1) the western Chinese government tends to favor the young and native talents, with a high initial academic degree (the degree obtained before working) and final academic degree (the highest degree obtained); (2) the talents with more experience, higher education, national talent titles, and participation in national projects are more likely to receive higher levels of funding; (3) it is easier for talents in universities and research institutes to be entitled as high-level talents and to gain funding than those in enterprises; and (4) talents in the fields of medicine, agronomy, and basic sciences are more likely to be entitled as high-level talents than those in other professional fields.

Keywords: talent selection, talent funding, high-level talents, resume, western China

\section{KEY POINTS}

- Collected the resume-related textual data of high-level talents and built a database of high-level talents in western China.

- Analyzed the influence of factors on the selection and funding of high-level talents based on the resumes of high-level talents in western China.

- Compared the selection and funding of high-level talents in different institutions and professional fields.

\section{INTRODUCTION}

In China, the selection and funding of high-end talents have always been the effective means for regions to complement the tactic of "innovation-driven development." The talent strategy of China has been the focus of the domestic and foreign academic circles (Zweig, 2006; Zhao and Leng, 2019) and aroused heated discussions in recent years (Wang, 2011; Niu and Zhou, 2012; Zhou et al., 2018). Since the inception of the People's Republic of China, from the "Academicians Program" headed by the Chinese Academy of Sciences (CAS, 1955) and the Chinese Academy of Engineering (CAE, 1994) to the national key high-level talent selection programs such as the "Thousand Talents Program" (TTP, 2008) and "Ten Thousand Talents Program" (TTTP, 2012), and high-level talent funding programs such as the "National Science Fund for Distinguished Young Scholars" (NSFDYS, 1994) and the "Chang Jiang Scholars Program" (CJSP, 1998), it has formed a complete 
selection and funding system for high-level talents, which is conducive to the cultivation and selection of the outstanding talents in China. Besides, local governments in China have launched a series of talent and funding programs, such as the "Phoenix Program" in Beijing, the "Hongyan Program" in Chongqing, and the "Bagui Scholars" in Guangxi. However, in the underdeveloped areas of western China, the difficulty in attracting, retaining, and cultivating talents has increasingly become the primary issue to be solved in the strategic adjustment of talents. Therefore, this study explored what factors should be highlighted in the selection and funding of high-level talents for the underdeveloped regions in China.

The existing research mainly analyzes talent selection from the perspective of the enterprise and examines the impacts of the knowledge, skills, and motivation of talents on the talent selection based on the "competency model” (McClelland, 1973; McLagan, 1980; Boyatzis, 1982). The research objects are mainly the corporate talents (Boyatzis, 1982; Bueno and Tubbs, 2004; Morrison, 2007), whereas few studies explore the selection of talents by local governments. Therefore, it lacks research on talent selection led by governments to promote regional scientific and technological innovation capacities. In terms of research methods, most research adopted the questionnaire survey (Chong, 2013; Skorková, 2016), but this method can hardly avoid measurement errors caused by subjective answers to some extent.

In this regard, this study included the high-level talents selected by the government as the research objects and explored the factors affecting the selection and funding of high-level talents in western China through the textual data of the resumes of 499 high-level talents. This study has the following three marginal contributions: First, it collected the resumerelated textual data of high-level talents for the first time and built the database of high-level talents in western China. Second, based on the textual data of 499 resumes of highlevel talents in western China, it empirically analyzed the influence of individual factors on the selection and funding of high-level talents and attempted to compare the selection and funding of high-level talents in different institutions and professional fields. Third, the results of this study can provide a scientific basis for the selection, funding, and cultivation of talents in remote areas, as well as suggestions for the academic career planning and development of highlevel talents.

The remaining part of this article is organized as follows: the "Literature review and research hypotheses" section reviews the related literature and develops research hypotheses. The "Research design" section involves the design of the research, the interpretation of the research data sources, and main variables. The empirical results and discussion follow in the "Research results" section. The "Further analyses: Heterogeneity test of institution and professional field" section reports the heterogeneity test of different institutions and professional fields. Finally, the "Discussion and conclusion" section summarizes and concludes.

\section{LITERATURE REVIEW AND RESEARCH HYPOTHESES}

The factors affecting the selection and funding of high-level talents mainly involve three aspects, namely, personality, human capital, and cumulative advantage.

\section{Personality and Talent Selection}

Personality is an important factor for success (Feist, 1998).

Studies have found that demographic characteristics such as age, gender, and birthplace will have an impact on the selection and funding of high-level talents. Human creativity is bound up with age (Manniche and Falk, 1957; Simonton, 1988; Baffes and Vamvakidis, 2011). At present, there are two explanations for the relationship between age and scientific research output of talents: First, some scholars reckon that the best creative age for the scientific elites presents the unimodal shape. Taking the age distribution of Nobel laureates as an example, physics laureates are younger than scientists in the field of economics (Bjork, 2019). Studies have found that the age of the highest professional achievement of top scientists gradually shifts back, and the peak age of scientific research is also moving backward (Jones and Weinberg, 2011). Furthermore, the Chinese scholars have also found that the recipients of major national science funds have an older trend (Han and Li, 2016). Second, others deem that the best creative age of most ordinary researchers shows the bimodal or the inverted U-shaped model. After the academic value created by an individual reaches its peak in the mature period, academic creativity will slowly decline (Aksnes et al., 2011).

From the perspective of the growth characteristics of scientific and technological talents, the performance of scientific and technological talents has phase characteristics (Zhang et al., 2018). Talent funding projects run through the entire life cycle of the career development of scientific and technological talents and promote the cultivation of scientific research ability and career development of scientific and technological talents, exchanges and cooperation of international talents, etc. (Zhang et al., 2017). Moreover, funding can significantly improve scientific productivity, maintain participation in the science department, and affect "brain drain" (Ganguli, 2017). The current research has also found that there are some management difficulties such as uneven distribution of disciplines, excessive proportion of introduced talents, obvious gender differences, and regional preferences in the funding of the Outstanding Youth Science Fund and the National Outstanding Youth Science Fund, which restrict the economic and technological development of underdevelopment regions in China (Zhao et al., 2017). In the youth talent funding programs in China, the proportion of women is lower than that of men (Wang and Ren, 2013), that is, men are more likely to obtain funding for scientific research projects than women (Symonds et al., 2006).

From the perspective of the preference of the talents for geographical location, some scholars pointed out that due to the resource endowment advantages of developed cities, the Chinese scientists are more willing to move to the eastern region, resulting in the spatial distribution of the Chinese scientists showing more in the east and less in the west (Wu et al., 2003; 
Abel and Deitz, 2009). From the perspective of the institution, talents are more willing to work in areas with many colleges and universities, which can provide numerous opportunities for the development of talents. The study found that the funders of the NSFDYS ("Jieqing") tend to gather in the southeast region, and there is a significant input of talent from universities. Therefore, the high-level youth talents in China are more likely to work in "prestigious universities and research institutes" (Rui, 2017). However, in recent years, it has shown a trend that more and more talents choose to work in western China (Harvey, 2014), which may be attributed to policy factors, family factors, and the pursuit of self-actualization of the individuals (Ioannidis, 2004; Soon, 2010a,b). Therefore, this study proposes the following hypotheses:

Hypothesis 1a: The older the talents, the more likely they are to be selected as high-level talents and to receive a higher level of academic recognition and gain more funding.

Hypothesis 1b: Compared to female talents, male talents are more likely to be selected as high-level talents and to receive a higher level of academic recognition and gain more funding.

Hypothesis 1c: Compared to talents in other regions, the native Guangxi talents are more likely to be selected as high-level talents and to receive a higher level of academic recognition and gain more funding.

\section{Human Capital and Talent Selection}

Human capital is an important factor affecting talent selection. Individual knowledge, education, skills, and health are the key elements that constitute human capital (Schultz, 1961). The human capital possessed by individuals can be assessed on the basis of their educational background, work experience, and identifiable skills (Harrison et al., 2001). The factors, including educational background, work experience, and professional skills (Tharenou et al., 1994; Kirchmeyer, 1998), have more impacts on individual career success. Besides, the factors, such as education level, education quality, job involvement, work experience, and length of service, are positively related to career success $(\mathrm{Ng}$ et al., 2005; Ballout, 2007). Therefore, education level, education quality, and work experience are the important factors that affect career success.

Empirical studies have revealed that the factors, such as education, intelligence, work competitiveness, and technical skills, are highly correlated with individual career success (Keeton, 1993). At different life stages, these factors have different impacts on career success (Seibert et al., 1999). Educational background, major, graduate school, and work experience have positive effects on the career success of American executives (Judge et al., 1999). In particular, educational background, graduate school, and post-doctoral experience have positive impacts on the growth of scientific researchers, especially on those who receive a strict formal education or obtain a doctorate from a prestigious school (Zuckerman and Jonathan, 1976). The experience of being selected and funded is part of career success. By measuring the human capital of talents, it can effectively predict the possibility of being selected and funded. Therefore, this study proposes the following hypotheses:
Hypothesis 2a: The higher education level the talents have, the more likely they are to be selected as high-level talents and to receive a higher level of academic recognition and gain more funding.

Hypothesis 2b: Compared to talents from the non-prestigious schools, those from prestigious schools are more likely to be selected as high-level talents and to receive a higher level of academic recognition and gain more funding.

Hypothesis 2c: The longer the length of service in Guangxi, the more likely talents are to be selected as high-level talent and to receive a higher level of academic recognition and gain more funding.

Hypothesis 2d: Compared to talents without skills certificates, those with skills certificates are more likely to be selected as high-level talents and to receive a higher level of academic recognition and gain more funding.

\section{Cumulative Advantage and Talent Selection}

The growth of an outstanding scientist fully reflects the "cumulative advantage" (Merton, 1968, 1973, 1988). The accumulation of advantages is mainly reflected in the honorary titles obtained by individual talents, published articles and studies, overseas study experience, and funding. Even in many cases, these indicators have become an important basis for the Chinese local governments to select talents.

In China, the "TTP," "Hundred Talents Program," “TTTP”, "CJSP," "Outstanding Youth," and other titles reflect the academic qualification and scientific research influence of talents to some extent (Niu and Zhou, 2012), and the obtainment of these titles can significantly enhance the achievement motivation of scientific and technological talents (Wang et al., 2020). For academic institutions, the introduction of talents with the title of "TTP" can lead to strong academic productivity and influence (Zhao and Ye, 2014). In fact, scientists with the title of "Hundred Talents Program" have comprehensively improved various institutes of the Chinese Academy of Sciences, in terms of the quantity and quality of the international academic articles (Li and $\mathrm{Ha}, 2017$ ).

In addition, many scholars believe that talent funding shows obvious features of funding concentration, that is, the Matthew effect (Leydesdorff et al., 2019). Recent studies have also found that talent funding projects are increasingly concentrated in the hands of a few researchers (Bol et al., 2018; Liao, 2021). However, some studies have also found that the other funded high-end scientific and technological talents in China have increasingly close cooperation at home and abroad in the scientific research output, and the effect is significant (Liu and Yang, 2017). However, the output of the Chinese Natural Science Youth Projects is mostly the foreign journals, the completion rate fluctuates greatly, and the conversion rate of scientific and technological achievements is not high (Rui, 2017). Moreover, the amount of funding received by most research institutions is negatively correlated with the output of the Chinese scientific research in the institution (Yin et al., 2018), i.e., there is no absolute positive correlation between the funding received by talents and the output of individual scientific research. Many researchers in the world use project funding to promote their 
own career development. Generally speaking, the pass rate is not high. In particular, early career researchers (ECRs) have a greater failure rate, which will lead to the loss of ECR talents (de Winde et al., 2021). From the individual level, researchers need to face reality and maintain hope (Holdsworth, 2020); from the institutional level, the government optimizes funding selection, making it more legal and scientific and boosting the career development of the research personnel (Besselaar and Arensbergen, 2013).

As a result, with the increase in government funding for talents, more attention has been paid to talent funding research, focusing on the status of funded projects and the analysis of the research output of project funders and their individual characteristics. Social network analysis and data analysis are used as the main methods in these studies, while resume analysis, questionnaire survey, and other attempts are rarely used. In data processing, descriptive statistical analysis dominates, and there are not many processing methods such as regression analysis. In general, there are many digable themes in the field of talent funding, such as the individual growth law of funded recipients and the performance results of funded projects, enriching the research content of this field. Therefore, this study proposes the following hypotheses:

Hypothesis 3a: The higher the titles talents have, the more likely they are to be selected as high-level talents and to receive a higher level of academic recognition and gain more funding.

Hypothesis 3b: Compared to talents without overseas study experience, those with overseas study experience are more likely to be selected as high-level talents and to receive a higher level of academic recognition and gain more funding.

Hypothesis 3c: Compared to talents without titles, those with titles are more likely to be selected as high-level talents and to receive a higher level of academic recognition and gain more funding.

Hypothesis 3d: Compared to talents without scientific research achievements, those with scientific research achievements are more likely to be selected as high-level talents and to receive a higher level of academic recognition and gain more funding.

\section{RESEARCH DESIGN}

\section{Data Sources}

\section{Data Collection}

The data source of this study is based on the Academic Recognition Measures for High-level Talents in Guangxi Zhuang Autonomous Region (No. 36 [2017] of Guibanfa). With the help of the Department of Human Resources and Social Security of Guangxi Zhuang Autonomous Region, a list of 499 high-level talents (only 336 of them were selected as the high-level talents) were obtained, and the resume data of these talents were collected in the later stage. The title of high-level talents discussed in this study is the provincial-level title, which specifically refers to the high-level innovative talents working in Guangxi. Based on the performance, contribution, industry, and social recognition of the talents, the title is divided into five levels from high to low, namely, A, B, C, D, and E.

\section{Data Cleaning}

By browsing the authoritative websites and querying the china national knowledge infrastructure (CNKI) database, the data matching and data improvement were carried out on the collected list of 499 talents. Then, combined with the field investigation and telephonic interviews, we established a basic resume database of 499 talents and figured out whether these talents had obtained the title of high-level talents. Overall, we collected the basic information, such as the age, gender, academic background, hometown (native of Guangxi or not), educational background, length of service in Guangxi, graduation institution, overseas study experience, scientific research results, and title and funding status of the talents.

\section{Variable Measurement}

The dependent variables are as follows: "whether to obtain the title of high-level talent," "the level of academic recognition," and "the amount of funding received."

Whether to obtain the title of high-level talent refers to whether candidates were selected as high-level talents. The level of academic recognition refers to the different levels (as mentioned earlier, there are five levels, i.e., A, B, C, D, and E) given to the selected 499 talents. The amount of funding received includes post-allowance, housing allowance, and team allowance, all of which are continuous variables.

The independent variables are as follows: "personality," "human capital," and "cumulative advantage."

Personality includes these measurement indicators, such as age, gender, and hometown (native of Guangxi or not). Human capital includes education level, graduate school, work experience, and skills certificate. Education level includes two variables, namely, initial academic degree (the degree obtained before working) and final academic degree (the highest degree obtained). Cumulative advantage includes professional qualification, overseas study experience, talent title, and nationallevel project. For more details, refer to Table 1.

\section{RESEARCH RESULTS}

\section{Model Design}

As "talent selection" is an ordered variable, we employed logit regression and ordinary least square (OLS) regression to analyze the factors affecting this variable, based on the control of the clustering effect of the location of the institution, professional field, and institution.

The dependent variables included here "whether to obtain the title of high-level talent," "level of academic recognition," and "the amount of funding received" denote the regression coefficient corresponding to each independent variable, indicating the fixed effect. The three fixed effects, namely, the location of the institution, professional field, and institution denote the coefficient corresponding to the fixed effects, indicating the random error. 
TABLE 1 | Value nd descriptive statistics of each variable.

\begin{tabular}{|c|c|}
\hline Variables & Descriptions \\
\hline \multicolumn{2}{|l|}{ Dependent variables } \\
\hline Title of high-level talent & No $=0$, yes $=1$ \\
\hline Level of academic recognition & Level $A=5$, Level $B=4$, Level $C=3$, Level $D=2$, Level $E=1^{a}$ \\
\hline Post-allowance & It refers to the relevant funding provided to talents for their scientific research. Please see the actual data. \\
\hline Housing allowance & $\begin{array}{l}\text { It refers to the funding provided by the local government to solve the housing issue of talents. Please see } \\
\text { the actual data. }\end{array}$ \\
\hline Team allowance & $\begin{array}{l}\text { It refers to necessary scientific research funding and support for talents to conduct research in a team. } \\
\text { Please see the actual data. }\end{array}$ \\
\hline \multicolumn{2}{|l|}{ Independent variables } \\
\hline \multicolumn{2}{|l|}{ Personality } \\
\hline Age & 2020-Year of birth \\
\hline Hometown & No $=0$, yes $=1$ \\
\hline Gender & Female $=0$, male $=1$ \\
\hline \multicolumn{2}{|l|}{ Human capital } \\
\hline Initial academic degree & Below junior college $=0$, junior college $=1$, bachelor $=2$, master $=3$, doctor $=4$, post-doctor $=5$ \\
\hline Final academic degree & Below junior college $=0$, junior college $=1$, bachelor $=2$, master $=3$, doctor $=4$, post-doctor $=5$ \\
\hline Key university & Non-211 or non-985 $=0,211=1,985=2,211$ and $985=3^{b}$ \\
\hline Length of service in Guangxi & Deadline of work contract-Start time of work contract \\
\hline Skills certificate & No $=0$, yes $=1$ \\
\hline \multicolumn{2}{|l|}{ Cumulative advantage } \\
\hline Professional qualification & No $=0 ;$ junior $=1 ;$ intermediate $=2 ;$ senior $=3 ;$ professor $=4^{c}$ \\
\hline Overseas talent & $\mathrm{No}=0, \mathrm{Yes}=1^{\mathrm{d}}$ \\
\hline Number of national-level titles & $\begin{array}{l}\text { It refers to the number of honorary titles obtained by participating in national-level talent selection } \\
\text { programs. Please see the actual data. }\end{array}$ \\
\hline Number of national-level funding & $\begin{array}{l}\text { It refers to the number of funded projects obtained by participating in the selection of national-level talent } \\
\text { funding projects. Please see the actual data. }\end{array}$ \\
\hline Number of provincial-level titles & $\begin{array}{l}\text { It refers to the number of honorary titles obtained by participating in provincial-level talent selection } \\
\text { programs. Please see the actual data. }\end{array}$ \\
\hline
\end{tabular}

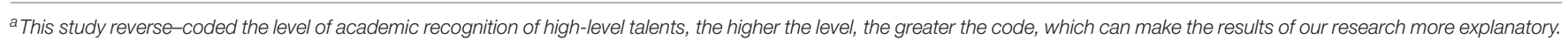

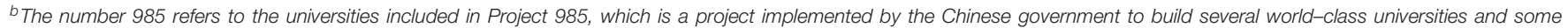

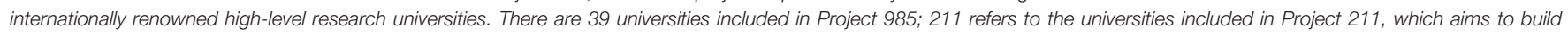
about 100 key universities and several key disciplines in the twenty-first century. There are 114 universities included in Project 211.

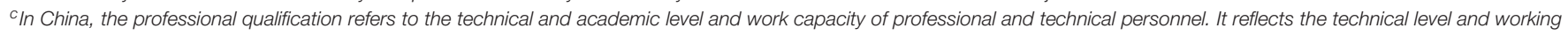
capacity of professional and technical personnel. It is mainly divided into junior, intermediate, and senior levels.

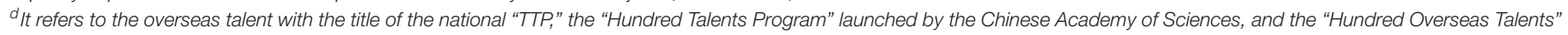

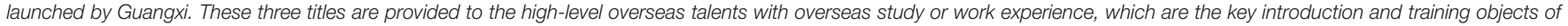
the state, institutions, or local governments.

\section{Model Test}

This study cross-checked the predictive effect of the model, and the specific method is as follows: K-fold Cross Validation was applied to cross-check the model, and the samples were divided into 10 groups. Finally, the correctly classified variable value prediction of the training data of the model was $89.18 \%$. The correctly classified variable value prediction obtained by training the model with the cross-check method was $87.58 \%$, the area under the curve (AUC) value of all samples was 0.9267 , and the AUC value of the test samples was 0.9057 . It can be observed that the fit of all data training models and cross-check training models was high, so the prediction effect of this model was good.

\section{Dependent and Independent Variables}

Table 2 describes the statistical characteristics of the dependent and independent variables. It can be observed that the average value of the dependent variable "whether to obtain the title of high-level talent" is 0.68 , and the average value of the variable "level of academic recognition" is 1.64 , indicating that $70 \%$ of the 499 talents obtained the title of high-level talent, and the "level of academic recognition" of most talents is D or E. Among the three types of allowances, the highest is "housing allowance." In terms of the "personality" the average value of "age" is 48.5 years old, the average value of "hometown" is 0.48 , and the average value of "gender" is 0.83 , that is, among the 499 talents, half of them are from Guangxi and male talent is predominant. The average values of variables "initial academic degree," "final academic degree," "key university," and "length of service in Guangxi" are $1.37,3.08,0.57$, and 16.77, respectively, indicating that among the candidates, most of them have a bachelor's degree or above in the "initial academic degree," master's degree in the "final academic degree," whereas they did not graduate from prestigious 
TABLE 2 | Descriptive statistics of related variables.

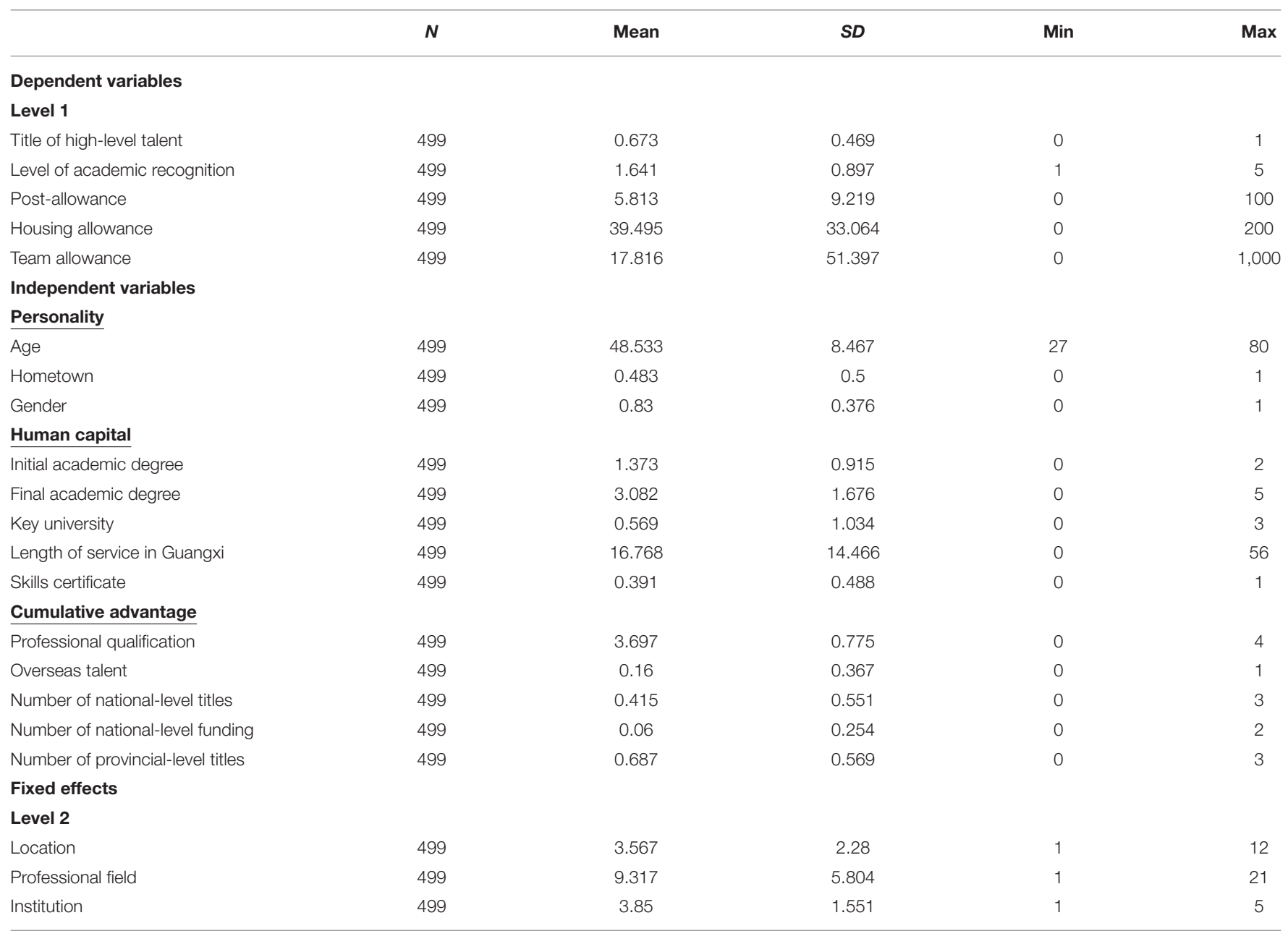

schools, and have worked in Guangxi for a long time. In terms of the "cumulative advantage," the average value of the variable "professional qualification" is 3.70, that is, most talents have senior titles or they are professors; the average value of "overseas talents or not" is 0.16 , that is, only a few of them have obtained the titles of "Thousand Talents Plan," "Hundred Talents Plan," and the "Hundred Overseas Talents" launched by Guangxi. The average values of "national-level title," "national-level project," and "provincial-level title" are 0.42, 0.06, and 0.69, respectively. That is to say, only a few talents have participated in the nationallevel projects. More results from the OLS estimation are reported in Appendix B (Supplementary Material).

\section{Hypothesis Testing}

Hypothesis testing of the influence of "personality" on talent selection (Table 3). As shown in Table 3, young people are more likely to obtain the "title of high-level talent," while the elderly are more likely to obtain a higher "level of academic recognition." Thus, Hypothesis 1a is partially supported. With regard to the testing of Hypothesis $1 \mathrm{~b}$, the regression results indicate that "gender" does not have a significant impact on talent selection. Therefore, this hypothesis is rejected. Hypothesis $1 \mathrm{c}$ is also partially supported. The regression results reveal that talents from Guangxi are more likely to obtain the "title of high-level talent," but the "hometown" does not affect the "level of academic recognition" of talents.

Hypothesis testing of the influence of "human capital" on talent selection. As the regression results show, if talents have a higher "initial academic degree" and "final academic degree," they will be more likely to obtain the "title of high-level talent." Besides, the "final academic degree" further affects the "level of academic recognition." Thus, Hypothesis $2 \mathrm{a}$ is almost supported. With respect to the testing of Hypothesis $2 \mathrm{~b}$, the regression results indicate that talents graduating from prestigious schools, such as universities included in Project 985 or Project 211, are more likely to obtain the "title of high-level talent." With regard to the testing of Hypothesis $2 \mathrm{c}$, the regression results manifest that this hypothesis is rejected at the $5 \%$ level of significance, that is, under the same conditions, it is easier for talents with a shorter "length of service in Guangxi" to obtain the "title of high-level talent." In terms of the testing of Hypothesis $2 \mathrm{~d}$, the regression results show that the "skills certificate" has no significant impact on the 
TABLE 3 | Regression results of related variables.

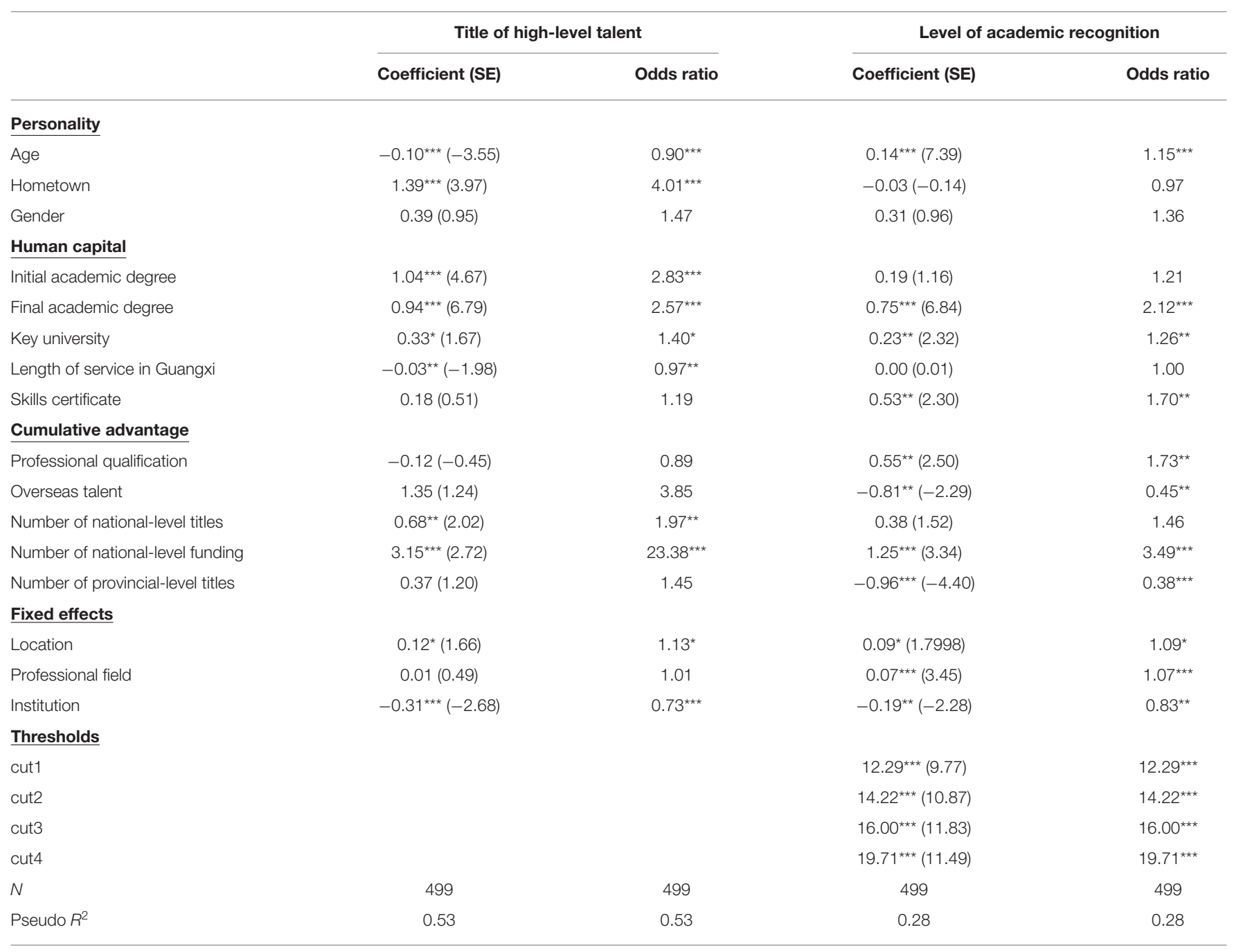

${ }^{*} p<0.10,{ }^{* *} p<0.05$, and ${ }^{* \star} p<0.01$.

obtainment of talents of the "title of high-level talent." However, under the same conditions, a skills certificate improves the "level of academic recognition."

Hypothesis testing of the impact of "cumulative advantage" on talent selection. Except for Hypothesis 3b, others are supported in varying degrees. As the regression results show, talents with high "professional qualification" are more likely to obtain the high "level of academic recognition," that is, Hypothesis 3a is supported. However, for Hypothesis $3 b$, the regression results manifest that, under the same conditions, those with "overseas study experience" have no advantage in gaining the "title of highlevel talent," and the "overseas study experience" is not conducive to the obtainment of high "level of academic recognition." In terms of the testing of the Hypothesis $3 \mathrm{c}$, the regression results show that it is easier for the talents with "national-level title" to be selected as the "high-level talent" than those with "provinciallevel title," and the more the talents with "provincial-level title" obtain, the less they are likely to gain high "level of academic recognition." With respect to the testing of Hypothesis $3 \mathrm{~d}$, the regression results indicate that the participation of "national-level projects" has a significant positive impact on talent selection.

The regression analysis was performed with "post-allowance," "housing allowance," and "team allowance" as dependent variables (Table 4). As shown in Table 4, "age" has statistically significant effects on "post-allowance," "housing allowance," and "team allowance," but the effects of "hometown" and "gender" on them are not significant. This indicates that the older the talents, the more likely they obtain allowance. "Human capital" as a whole has a significant influence on "post-allowance," "housing allowance," and "team allowance," indicating that the funding policies in the underdeveloped regions favor talents with higher education level and from famous universities. The "length of service in Guangxi" negatively affects "housing allowance" and "team allowance," indicating that the shorter the "length of service in Guangxi," the easier the talents obtain funding. This may be related to the preference of funding 
TABLE 4 | Regression results of different funding.

\begin{tabular}{|c|c|c|c|}
\hline & $\begin{array}{l}\text { Post-allowance } \\
\text { Coefficient (SE) }\end{array}$ & $\begin{array}{l}\text { Housing allowance } \\
\text { Coefficient (SE) }\end{array}$ & $\begin{array}{l}\text { Team allowance } \\
\text { Coefficient (SE) }\end{array}$ \\
\hline \multicolumn{4}{|l|}{ Personality } \\
\hline Age & $0.36^{\star \star \star}(6.27)$ & $1.44^{\star \star \star}(7.07)$ & $1.94^{\star \star \star}(5.54)$ \\
\hline Hometown & $-0.72(-0.96)$ & $-2.09(-0.79)$ & $-6.79(-1.48)$ \\
\hline Gender & $0.67(0.72)$ & $2.41(0.73)$ & $0.10(0.02)$ \\
\hline Final academic degree & $1.31^{\star \star \star}(4.38)$ & $5.33^{\star \star \star}(5.03)$ & $4.34^{\star \star}(2.37)$ \\
\hline Key university & $0.50(1.37)$ & $2.80^{* \star}(2.14)$ & $-0.27(-0.12)$ \\
\hline Length of service in Guangxi & $0.04(1.20)$ & $-0.23^{\star \star}(-2.02)$ & $-0.41^{\star \star}(-2.06)$ \\
\hline Skills certificate & $1.48^{\star}(1.89)$ & $7.25^{\star \star \star}(2.61)$ & $6.17(1.29)$ \\
\hline \multicolumn{4}{|l|}{ Cumulative advantage } \\
\hline Number of national-level funding & $3.46^{\star \star}(2.41)$ & $15.54^{\star \star \star}(3.05)$ & $19.28^{\star \star}(2.19)$ \\
\hline Number of provincial-level title & $-2.73^{\star \star \star}(-3.92)$ & $-8.86^{\star \star \star}(-3.59)$ & $-5.85(-1.37)$ \\
\hline \multicolumn{4}{|l|}{ Fixed effects } \\
\hline Location1 & $0.39^{\star \star}(2.53)$ & $-0.19(-0.34)$ & $0.60(0.63)$ \\
\hline Professional field 1 & $0.15^{\star \star}(2.34)$ & $0.60^{\star \star \star}(2.66)$ & $0.31(0.79)$ \\
\hline Institution1 & $0.04(0.14)$ & $-1.12(-1.23)$ & $-0.07(-0.04)$ \\
\hline _cons & $-22.22^{\star \star \star}(-8.09)$ & $-58.11^{\star \star \star}(-5.95)$ & $-101.55^{\star \star \star}(-6.03)$ \\
\hline N & 499 & 499 & 499 \\
\hline Pseudo $R^{2}$ & & & \\
\hline
\end{tabular}

${ }^{*} p<0.10,{ }^{* \star} p<0.05$, and ${ }^{* \star *} p<0.01$.

policies in the underdeveloped regions, hoping to attract more young talents through funding policies. The obtainment of "skills certificates" also makes it easier to get "post-allowance" and "housing allowance." As for the "cumulative advantage," "national-level title" and "national-level project" have significant effects on the three types of allowances, indicating that the funding policies of the underdeveloped regions do not favor talents with "professional qualifications" and "overseas study experience" but prefer talents who have obtained "national-level titles" and participated in "national-level projects." It is worth mentioning that talents with "provincial-level titles" have no advantage in obtaining relevant funding.

\section{FURTHER ANALYSES: HETEROGENEITY TEST OF INSTITUTION AND PROFESSIONAL FIELD}

\section{The Impact of Different Institutions on Talent Selection}

We explored the influence of the different "institutions" on the obtainment of the "title of high-level talent," the "level of academic recognition," and the "amount of funding received" (Table 5). The results show that compared to the talents in "enterprises," the talents in "scientific research institutes" are more likely to obtain "title of high-level talents," gain high "level of academic recognition," and get "post-allowance."
Compared to talents in "enterprises," those in "universities" have no significant advantage in obtaining the "title of highlevel talent." However, it is easier for talents in "universities" to obtain post and housing allowances than those in "enterprises." We provided three possible explanations for this difference. First, the scientific research conditions and environment of "universities" and "scientific research institutes" are better than those of "enterprises," so talents in "universities" and "scientific research institutes" are more likely to achieve good scientific research results that are expected of government funding. Second, the various funds given by the state or local government to "universities" and "scientific research institutes" are more abundant than those of "enterprises." In addition, local "universities" and "scientific research institutes" are the gathering places of high-level talents, so they need more talent funding and training than enterprises. We also found that talents in "other public institutions" have no advantage in obtaining the "title of high-level talent" compared to those in "enterprises," indicating that under the same conditions, talents in "enterprises" are more likely to be selected as high-level talents than those in "other public institutions."

\section{The Impact of Different Professional Fields on Talent Selection}

We examined the influence of different "professional fields" on the obtainment of the "title of high-level talent," the "level of 
TABLE 5 | The impact of different institutions on talent selection and funding.

\begin{tabular}{clccc}
\multicolumn{2}{c}{ Logit regression } \\
\hline Title of high-level talent & & \multicolumn{2}{c}{$\begin{array}{c}\text { Level of academic } \\
\text { recognition }\end{array}$} \\
\cline { 1 - 2 } $\begin{array}{c}\text { Coefficient } \\
\text { (SE) }\end{array}$ & $\begin{array}{l}\text { Odds } \\
\text { ratio }\end{array}$ & & $\begin{array}{c}\text { Coefficient } \\
\text { (SE) }\end{array}$ & $\begin{array}{c}\text { Odds } \\
\text { ratio }\end{array}$
\end{tabular}

\begin{tabular}{|c|c|c|}
\hline \multicolumn{3}{|c|}{ OLS regression } \\
\hline Post-allowance & $\begin{array}{l}\text { Housing } \\
\text { allowance }\end{array}$ & Team allowance \\
\hline $\begin{array}{l}\text { Coefficient } \\
\text { (SE) }\end{array}$ & $\begin{array}{l}\text { Coefficient } \\
\text { (SE) }\end{array}$ & $\begin{array}{l}\text { Coefficient } \\
\text { (SE) }\end{array}$ \\
\hline
\end{tabular}

\section{Institution}

Enterprise

Other public

institutions

Hospital

Scientific

research

institute

University

_cons

$0.00($.
$-1.27^{\star}(-1.76)$

0.00

$0.28^{\star}$

$0.00($.

$0.35(0.53)$

1.16

$0.15(0.36)$
$0.62 *(1.92)$

$1.85^{\star}$

$0.40(1.62)$

$0.42^{\star \star}(2.03)$

1.49
$1.52^{\star *}$

$0.13(0.35)$

$0.52^{*}(1.82)$

$0.40^{\star}(1.65)$

$-$

$0.68^{\star \star \star}(3.30)$
$1.87^{\star \star \star}(8.38)$
$3.24^{\star \star \star}(11.60)$
$6.55^{\star \star \star}(6.42)$
499

499

0.0165

0.0040

cut1

cut2

cut3

N

Pseudo $R^{2}$

${ }^{\star} p<0.10,{ }^{* \star} p<0.05$, and ${ }^{* \star *} p<0.01$

TABLE 6 | The impact of different professional fields on talent selection and funding.

\begin{tabular}{|c|c|c|c|c|c|c|c|}
\hline & \multicolumn{4}{|c|}{ Logit regression } & \multicolumn{3}{|c|}{ OLS regression } \\
\hline & \multicolumn{2}{|c|}{ Title of high-level talent } & \multicolumn{2}{|c|}{$\begin{array}{l}\text { Level of academic } \\
\text { recognition }\end{array}$} & \multirow{2}{*}{$\begin{array}{c}\text { Post-allowance } \\
\begin{array}{c}\text { Coefficient } \\
\text { (SE) }\end{array}\end{array}$} & \multirow{2}{*}{$\begin{array}{c}\begin{array}{c}\text { Housing } \\
\text { allowance }\end{array} \\
\begin{array}{c}\text { Coefficient } \\
\text { (SE) }\end{array}\end{array}$} & \multirow{2}{*}{$\begin{array}{c}\text { Team allowance } \\
\begin{array}{c}\text { Coefficient } \\
\text { (SE) }\end{array}\end{array}$} \\
\hline & $\begin{array}{l}\text { Coefficient } \\
\text { (SE) }\end{array}$ & $\begin{array}{l}\text { Odds } \\
\text { ratio }\end{array}$ & $\begin{array}{l}\text { Coefficient } \\
\text { (SE) }\end{array}$ & $\begin{array}{l}\text { Odds } \\
\text { ratio }\end{array}$ & & & \\
\hline \multicolumn{8}{|c|}{$\underline{\text { Professional fields }}$} \\
\hline $\begin{array}{l}\text { Other } \\
\text { professional } \\
\text { fields }\end{array}$ & $0.00()$. & & $0.00()$. & & $0.00()$. & $0.00()$. & $0.00()$. \\
\hline Agronomy & $2.52^{\star \star \star}(5.22)$ & $12.47^{\star \star \star}$ & $3.31^{\star \star \star}(3.18)$ & $27.29^{\star \star \star}$ & $5.24^{\star \star \star}(2.95)$ & $15.57^{\star \star}(2.44)$ & $14.61(1.44)$ \\
\hline Engineering & $1.69^{\star \star \star}(3.74)$ & $8.12^{\star \star \star}$ & $3.16^{\star \star \star}(3.05)$ & $18.80^{\star \star \star}$ & $3.40^{\star \star}(1.98)$ & $11.74^{*}(1.91)$ & $11.93(1.22)$ \\
\hline Medicine & $2.09^{\star \star \star}(4.67)$ & $5.41^{\star \star \star}$ & $2.93^{\star \star \star}(2.83)$ & $23.52^{\star \star \star}$ & $5.02^{\star \star \star}(2.99)$ & $17.96^{\star \star \star}(2.98)$ & $24.75^{\star \star \star}(2.59)$ \\
\hline Liberal arts & $1.34^{\star \star \star}(2.62)$ & $3.80^{\star \star \star}$ & $4.14^{\star \star \star}(3.93)$ & $62.52^{\star \star \star}$ & $9.34^{\star \star \star}(4.63)$ & $30.79^{\star \star \star}(4.24)$ & $10.52(0.91)$ \\
\hline Science & $3.14^{\star \star \star}(6.94)$ & $23.17^{\star \star \star}$ & $3.79^{\star \star \star}(3.70)$ & $44.21^{\star \star \star}$ & $7.19^{\star \star \star}(4.54)$ & $25.58^{\star \star \star}(4.50)$ & $23.43^{\star \star \star}(2.60)$ \\
\hline _cons & $-1.39^{\star \star \star}(-3.51)$ & $0.25^{\star \star \star}$ & - & - & $0.40(0.28)$ & $20.90^{\star \star \star}(4.10)$ & $0.25(0.03)$ \\
\hline \multicolumn{8}{|l|}{ Thresholds } \\
\hline cut1 & & & $3.67^{\star \star \star}(3.63)$ & $3.67^{\star \star \star}$ & & & \\
\hline cut2 & & & $4.94^{\star \star \star}(4.85)$ & $4.94^{\star \star \star}$ & & & \\
\hline cut3 & & & $6.34^{\star \star \star}(6.14)$ & $6.34^{\star \star \star}$ & & & \\
\hline cut4 & & & $9.65^{\star \star \star}(6.78)$ & $9.65^{\star \star \star}$ & & & \\
\hline$N$ & 499 & & 499 & & 499 & 499 & 499 \\
\hline Pseudo $R^{2}$ & 0.1223 & & 0.0516 & & & & \\
\hline
\end{tabular}

${ }^{\star} p<0.10,{ }^{* \star} p<0.05$, and ${ }^{\star \star *} p<0.01$. 
academic recognition," and the "amount of funding received" (Table 6). The results indicated that compared to the talents in "other professional fields," those engaged in "agronomy," "engineering," "medicine," "liberal arts," and "science" are more likely to be selected as high-level talents. Specifically, the number of talents in "science" who are selected as high-level talents is 23.17 times than those in "other professional fields," and the number of talents in "liberal arts" who obtained the high "level of academic recognition" is 62.52 times than those in "other professional fields." In terms of "team allowance," it is easier for talents in "medicine" and "science" to obtain "team allowance" than those in "agronomy," "engineering," "liberal arts," and "other professional fields." As far as post and housing allowances are concerned, talents in "liberal arts" gain the most post and housing allowances. It may be due to the following reasons: First, "medicine" and "science" are the basic research disciplines, with an emphasis on experiments and the formation of scientific research teams (deB Beaver and Rosen, 1978, 1979). Some studies have pointed out that experimental scientists are more cooperative than theoretical scientists (Gordon, 1980), especially in the field of basic research, which needs more cooperation than other non-basic fields (Newman, 2001). Therefore, basic sciences such as "medicine" and "science" need more funding, especially team funding, to better organize scientific research teams and conduct research. Second, "liberal arts" highlight theories. Compared to basic disciplines such as "science," "engineering," "medicine," and "agronomy," "liberal arts" have lower requirements for scientific research facilities, office conditions, and scientific research team building, but they have higher requirements for the platform.

\section{DISCUSSION AND CONCLUSION}

This study analyzed the text of resumes of high-level talents in western China, explored the factors affecting the selection of high-level talents, and revealed the mechanism behind the selection of high-level talents in the underdeveloped regions in western China. The results indicated that as follows: (1) in terms of talent selection, the selection of high-level talents in the underdeveloped regions in China favors the young and native talents, with high academic qualifications and degrees from prestigious schools. Additionally, the talents who have obtained the national-level titles and participated in the nationallevel projects are more likely to be selected as high-level talents. However, those with provincial-level titles have no advantage in talent selection; (2) with respect to funding, the talents with old age, high academic qualifications, nationallevel titles, and experience in national-level projects are more likely to obtain high funding for post, team, and housing allowances. However, the funding policies of the underdeveloped regions favor the talents with a short length of service in Guangxi; and (3) based on the heterogeneity analysis, we found that it is easier for talents in universities and scientific research institutes to obtain the title of high-level talent and gain funding than those in enterprises; the talents in medical, agronomy, and basic sciences are more likely to obtain a high level of academic recognition than those in other professional fields. With respect to the allowances received, talents in medicine and science are more likely to receive higher team allowances than those in other professional fields, and talents in literal arts tend to receive higher post and housing allowances. Therefore, the selection criteria of highlevel talents should be formulated according to the reality of the western regions.

This study can provide significant references for the formulation, implementation, and optimization of selection and training plans of high-level talents for the underdeveloped regions. First, age-related funding policies should be inclusive, and the selection of high-level talents should be reasonable in age distribution. We should not only attach importance to the selection, training, and funding of young talents but also give full play to the role of "cumulative advantage" in the career growth of middle-aged and elderly scientists and create conditions and opportunities for their second peak of scientific research creativity. Second, we should highlight the impacts of the non-traditional factors on the introduction of high-level talents, from relying solely on material support to providing both material and non-material supports. Third, local governments should formulate innovative talent incentive and security policies, strengthen and develop the endogenous motivation of talent incentive mechanism, and take into account the competitive relationship between foreign talents and local talents. Moreover, it is necessary to value the talents who have been working in Guangxi for a long time and have made great contributions to the region, while making use of the funding policies to attract young talents. Fourth, it is necessary to give play to the incentive role of the non-material support, as well as the guarantee function of the material support such as funding policies. The number of allowances for various professional fields should be allocated reasonably, and more post and team allowances should be given to talents in basic disciplines. The talents in liberal arts should gain more funding in housing. Fifth, the selection of talents should not only consider "academic qualifications," "titles," and "projects." In other words, the selection and cultivation of talents in the underdeveloped regions should facilitate the local scientific and technological progress, the high-quality economic development, and the transformation and upgrading of industrial structure. Finally, it is necessary to improve the scientific research facilities of local universities and scientific research institutes and to create an excellent scientific research atmosphere, so as to provide sufficient space for talents to make use of their capacities.

This study has some limitations. First, this study mainly explored the individual factors affecting the selection of highlevel talents in western China. Apart from these factors, there might be other influencing factors, such as the attractiveness of local talent policies, the level of regional competitiveness, and the organizational support. Second, the independent variables involved in this study may have hierarchical relationships, but we did not explore the relationship between the variables. Finally, this study did not discuss the teamlevel selection. Hence, future research can be improved in these aspects. 


\section{DATA AVAILABILITY STATEMENT}

The raw data supporting the conclusions of this article will be made available by the authors, without undue reservation.

\section{AUTHOR CONTRIBUTIONS}

JZ and FW: conceptualization, methodology, software, validation, formal analysis, resources, writing-original draft preparation, writing-review and editing, visualization, supervision, project administration, and funding acquisition. JS: investigation. JZ: data curation. All authors contributed to the article and approved the submitted version.

\section{FUNDING}

This research was financially supported by the project of the Philosophy and Social Science Planning Research of Guangxi (20FGL050), the fund project of the National Natural Science Foundation of China (Grant No. 71974203), the Zhongnan University of Economics and Law Fundamental Research

\section{REFERENCES}

Abel, J. R., and Deitz, R. (2009). Do colleges and universities increase their region's human capital? J. Econ. Geogr. 401, 667-691. doi: 10.1093/jeg/lbr020

Aksnes, D. W., Rorstad, K., Fredrik, P., and Sivertsen, G. (2011). "Age and scientific performance. A large-scale study of Norwegian scientists," in 13th Conference of the International Society for Scientometrics and Informetrics (ISSI) [Oslo: Nordic Institute for Studies in Innovation, Research and Education (NIFU)], 34-45.

Baffes, J., and Vamvakidis, A. (2011). Are you too young for the Nobel Prize? Res. Policy 40, 1345-1353. doi: 10.1016/j.respol.2011.06.001

Ballout, H. (2007). Career success: the effect of human capital, personenvironment fit and organizational support. J. Manager. Psychol. 22, 741-765. doi: 10.1108/02683940710837705

Besselaar, P., and Arensbergen, P. V. (2013). Talent selection and the funding of research. High. Educ. Policy 26, 421-427. doi: 10.1057/hep.2013.16

Bjork, R. (2019). The age at which Noble Prize research is conducted. Scientometrics 119, 931-939. doi: 10.1007/s11192-019-03065-4

Bol, T., de Vaan, M., and van de Rigt, A. (2018). The Matthew effect in science funding. Proc. Natl. Acad. Sci. U.S.A. 115, 4887-4890. doi: 10.1073/pnas.1719557115

Boyatzis, R. E. (1982). The Competent Manager: A Model for Effective Performance. New York, NY: John Wiley and Sons.

Bueno, C. M., and Tubbs, S. L. (2004). Identifying global leadership competencies: an exploratory study. J. Am. Acad. Bus. 5, 80-87. doi: $10.1177 / 0020852315576706$

Chong, E. (2013). Managerial competencies and career advancement: a comparative study of managers in two countries. J. Bus. Res. 66, 345-353. doi: 10.1016/j.jbusres.2011.08.015

de Winde, C. M., Sarabipour, S., and Carignano, H., Davla, S., Eccles, D. A., Hainer, S. J., et al. (2021). White paper: towards inclusive funding practices for early career researchers. J. Sci. Policy Governance 3, 2372-2193. doi: 10.31219/osf.io/9sfm8

deB Beaver, D., and Rosen, R. (1978). Studies in scientific collaboration. Part. I. The professional origins of scientific co-authorship. Scientometrics 1, 65-84. doi: 10.1007/BF02016840

deB Beaver, D., and Rosen, R. (1979). Studies in scientific collaboration. Part II. Scientific co-authorship, research productivity and visibility in French scientific elite, 1799-1830. Scientometrics 1, 133-49. doi: 10.1007/BF02016966
Funds for the Central Universities (2722021BX021), and the Innovation and Talent Base for Income Distribution and Public Finance (B20084).

\section{ACKNOWLEDGMENTS}

In particular, we would like to thank Qin Zhi from the Department of Human Resources and Social Security of Guangxi Province for her support and also thank Zhu Fangman, Fan Xuekai, Deng Mengyun, and Liu Xiangling, post-graduate students of Guangxi University, and Jiang Haile from the Guangxi University Xingjian College of Science and Liberal Arts and Lu Jingxian from the Jiamusi University for their efforts in the preliminary stage of data collection.

\section{SUPPLEMENTARY MATERIAL}

The Supplementary Material for this article can be found online at: https://www.frontiersin.org/articles/10.3389/fpsyg. 2021.687447/full\#supplementary-material

Feist, G. J. (1998). A meta-analysis of personality in scientific and artistic creativity. Pers. Soc. Psychol. Rev. 2, 290-309. doi: 10.1207/s15327957pspr0204_5

Ganguli, I. (2017). Saving soviet science: the impact of grants when government RandD funding disappears. Am. Econ. J. Appl. Econ. 9, 165-201. doi: 10.1257/app.20160180

Gordon, M. D. (1980). A critical reassessment of inferred relations between multiple authorship, scientific collaboration, the production of papers and their acceptance for publication. Scientometrics 2, 193-210. doi: $10.1007 / \mathrm{BF} 02016697$

Han, L. J., and Li, X. (2016). Older trend of distinguished youth science and its disadvantages - statistics and analysis on the age of gainer of distinguished youth science fund from 1994 to 2013. Forum Sci. Technol. China 9, 122-127. doi: 10.3969/j.issn.1002-6711.2016.09.020

Harrison, J. S., Hitt, M. A., Hoskisson, R. E., and Ireland, R. D. (2001). Resource complementarity in business combinations: extending the logic to organizational alliances. J. Manage. 27, 679-690. doi: 10.1177/014920630102700605

Harvey, W. S. (2014). Winning the global talent war: a policy perspective. J. Chin. Hum. Resour. Manag. 1:15. doi: 10.1108/JCHRM-01-2014-0003

Holdsworth, C. (2020). A manifesto for failure: depersonalising, collectivising and embracing failure in research funding. Emot. Space Soc. 37:100744. doi: 10.1016/j.emospa.2020.100744

Ioannidis, J. P. A. (2004). Global estimates of high-level brain drain and deficit. FASEB J. 18, 936-939. doi: 10.1096/fj.03-1394lfe

Jones, B. F., and Weinberg, B. A. (2011). Age dynamics in scientific creativity. Proc. Natl. Acad. Sci. U. S. A. 108, 18910-18914. doi: 10.1073/pnas.1102895108

Judge, T. A., Higgins, C. A., Thoresen, C. J., and Barrick, M. R. (1999). The big five personality traits, general mental ability, and career success across the life span. Pers. Psychol. 52, 621-652. doi: 10.1111/j.1744-6570.1999.tb00174.x

Keeton, K. B. (1993). Characteristics of successful women managers and professionals in local government: a national survey. Women Manage. Rev. 11, 27-34. doi: 10.1108/09649429610117434

Kirchmeyer, C. (1998). Determinants of managerial career success: evidence and explanation of male/female differences. J. Manage. 24, 673-692. doi: 10.1177/014920639802400601

Leydesdorff, L., Bornmann, L., and Wagner, C. S. (2019). The relative influences of government funding and international collaboration on citation impact. J. Assoc. 70, 198-201. doi: 10.1002/asi.24109 
Li, L., and Ha, W. (2017). The effect of "Hundred Talent Program" on research productivity at the Chinese academy of science (1993-2004). Tsinghua J. Educ. 38, 27-34 (in Chinese). doi: 10.14138/j.1001-4519.2017.05.002708

Liao, C. H. (2021). The Matthew effect and the halo effect in research funding. J. Informetr. 15:101108. doi: 10.1016/j.joi.2020.101108

Liu, Y., and Yang, F. J. (2017). Analysis on the characteristics of scientific research output of my country's high-end technological talent program. Sci. Res. Manag. 38, 610-622. doi: 10.19571/j.cnki.1000-2995.2017.s1.083

Manniche, E., and Falk, G. (1957). Age and the Nobel Prize. Behav. Sci. 2, 301-307. doi: 10.1002/bs.3830020407

McClelland, D. C. (1973). Testing for competence rather than for intelligence. Am. Psychol. 28, 1-14. doi: 10.1037/h0034092

McLagan, P. A. (1980). Competency models. Train. Dev. J. 34, 22-26.

Merton, R. K. (1968). The Matthew effect. Science 3810, 56-63. doi: $10.1126 /$ science.159.3810.56

Merton, R. K. (1973). The Sociology of Science: Theoretical and Empirical Investigations. Chicago, IL: University of Chicago Press.

Merton, R. K. (1988). The Matthew effect (II): cumulative advantage and the symbolism intellectual property. Isis 79, 606-623. doi: 10.1086/354848

Morrison, M. (2007). HBR Case Study: The Very Model of a Modern Senior Manager, Vol. 85. Boston, MA: Harvard Business Review, 27.

Newman, M. E. J. (2001). Scientific Collaboration Networks: network construction and fundamental results. Phys. Rev. E 64, 1-8. doi: $10.1103 /$ PhysRevE.64.016131

Ng, T. W. H., Eby, L. T., Sorensen, K. L., and Feldman, D. C. (2005). Predictors of objective and subjective career success: a meta-analysis. Pers. Psychol. 58, 367-408. doi: 10.1111/j.1744-6570.2005.00515.x

Niu, Y., and Zhou, J. Z. (2012). A characteristic study of the high-level S\&T talents in China based on CV analysis taking the projects or "hundred talents program", the "Yangtze River Scholar" and "outstanding youth" as examples. J. Univ. Sci. Technol. Beijing (Soc. Sci. Edn.) 28, 96-102. doi: 10.3969/j.issn.1008-2689.2012.02.016

Rui, L. (2017). Analysis on the funding and output of China's high-level young talents program - a case study of the "National Natural Science Foundation for Youth Program". China Youth Study 3, 75-80 (in Chinese). doi: 10.3969/j.issn.1002-9931.2017.03.011

Schultz, T. W. (1961). Investment in human capital. Econ. J. 82:787. doi: $10.2307 / 2230051$

Seibert, S. E., Crant, J. M., and Kraimer, M. L. (1999). Proactive personality and career success. J. Appl. Psychol. 84, 416-427. doi: 10.1037/0021-9010.84.3.416

Simonton, D. K. (1988). Age and outstanding achievement: what do we know after a century of research? Psychol. Bull. 104, 251-267. doi: 10.1037/0033-2909.104.2.251

Skorková, Z. (2016). Competency models in public sector. Proc. Soc. Behav. Sci. 230, 226-234. doi: 10.1016/j.sbspro.2016.09.029

Soon, J. J. (2010a). The determinants of students' return intentions: a partial proportional odds model. J. Choice Modell. 3, 89-112. doi: 10.1016/S1755-5345(13)70037-X

Soon, J. J. (2010b). When do students intend to return? Determinants of students' return intentions using a multinomial logit model. Int. J. Bus. Soc. 11, 17-32.

Symonds, M. R., Gemmell, N. J., Braisher, T. L., Gorringe, K. L., and Elgar, M. A. (2006). Gender differences in publication output: towards an unbiased metric of research performance. PLoS ONE 1:e127. doi: 10.1371/journal.pone.0000127

Tharenou, P., Latimer, S., and Conroy, D. (1994). How do you make it to the top? An examination of influences on Women's and Men's managerial advancement. Acad. Manage. J. 37, 899-931. doi: 10.5465/256604

Wang, H. Y. (2011). China's new talent strategy: impact on China's development and its global exchanges. SAIS Rev. Int. Affairs 31, 49-64. doi: 10.1353/sais.2011.0026
Wang, L. J., Dai, X. L., Jin, L., and Liu, Q. (2020). Can the title of talents increase career achievement motivation-based on the survey of scientific and technological talents in China's first-class universities. Sci. Technol. Progr. Policy 37, 153-160 (in Chinese). doi: 10.6049/kjjbydc.2019040261

Wang, X. H., and Ren, X. F. (2013). The exploratory analysis on management policy of science fund for excellent youth scholars. Bull. Natl. Nat. Sci. Found. China 27, 286-290. (in Chinese). doi: 10.16262/j.cnki.1000-8217.2013.05.010

Wu, D. T., Li, D. F., Liu, C., Zhang, R., Gu, S. D., and CAI, C. X. (2003). An analysis of environmental factors for the growth of senior scientific and technological talents - a case study of academicians of Chinese Academy of Sciences and Chinese Academy of Sciences (in Chinese). Stud. Dialect. Nat. 9, 54-63. doi: 10.19484/j.cnki.1000-8934.2003.09.013

Yin, Z. F., Liang, Z., and Zhi, Q. (2018). Does the concentration of scientific research funding in institutions promote knowledge output? J. Informetr. 12, 1145-1159. doi: 10.1016/j.joi.2018.09.003

Zhang, J., Wang, X. F., Liao, Q. Y., and Li, J. (2017). Performance evaluation of NSFC Talent Project based on questionnaire survey. Bull. Natl. Nat. Sci. Found. China 31, 481-488 (in Chinese). doi: 10.16262/j.cnki.1000-8217.2017.05.011

Zhang, W. S., Chen, R., and Liu, K., et al. (2018). Analysis of talent growth characteristics funded by NSFC: taking the leader of science fund for creative research groups as an example. Bull. Natl. Nat. Sci. Found. China 32, 382-386 (in Chinese).

Zhao, J. F., and Leng, W. Y. (2019). Research on China's high-level talent introduction pro-gram in the context of first-class universities - based on the three talent introduction programs of "Jie Qing", "Changjiang Scholar" and "1000 Talents". J. Beihua Univers. 20, 140-145 (in Chinese). doi: 10.19669/j.issn.1009-5101.2019.05.019

Zhao, J. F., and Ye, T. T. (2014). Quantitative research on the academic development power of the "Thousand Talents Plan" candidates - based on the top five candidates of "project 985" universities. China High. Educ. Res. 11, 43-48 (in Chinese). doi: 10.16298/j.cnki.1004-3667.2014.11.009

Zhao, W., Li, X. X., Wang, X. H., and Deng, H. X. (2017). Analysis on the funding status of "Youqing" and "Jieqing" in 2017. China Univers. Sci. Technol. 18-20. doi: 10.16209/j.cnki.cust.2017.s2.006

Zhou, Y., Guo, Y. Z., and Liu, Y. S. (2018). High-level talent flow and its influence on regional unbalanced development in China. Appl. Geogr. 91, 89-98. doi: 10.1016/j.apgeog.2017.12.023

Zuckerman, H., and Jonathan, C. (1976). Women in science. Minerva 13, 82-102. doi: 10.1007/BF01096243

Zweig, D. (2006). Competing for talent: China's strategies to reverse the brain drain. Int. Lab. Rev. 145, 65-90. doi: 10.1111/j.1564-913X.2006.tb00010.x

Conflict of Interest: The authors declare that the research was conducted in the absence of any commercial or financial relationships that could be construed as a potential conflict of interest.

Publisher's Note: All claims expressed in this article are solely those of the authors and do not necessarily represent those of their affiliated organizations, or those of the publisher, the editors and the reviewers. Any product that may be evaluated in this article, or claim that may be made by its manufacturer, is not guaranteed or endorsed by the publisher.

Copyright $\odot 2021 \mathrm{Wu}$, Su and Zeng. This is an open-access article distributed under the terms of the Creative Commons Attribution License (CC BY). The use, distribution or reproduction in other forums is permitted, provided the original author(s) and the copyright owner(s) are credited and that the original publication in this journal is cited, in accordance with accepted academic practice. No use, distribution or reproduction is permitted which does not comply with these terms. 